\title{
Correction to: cuRnet: an R package for graph traversing on GPU
}

Vincenzo Bonnici ${ }^{1}$, Federico Busato ${ }^{1}$, Stefano Aldegheri ${ }^{1}$, Murodzhon Akhmedov², Luciano Cascione ${ }^{2}$, Alberto Arribas Carmena ${ }^{2}$, Francesco Bertoni ${ }^{2}$, Nicola Bombieri ${ }^{1}$, Ivo Kwee ${ }^{2}$ and Rosalba Giugno ${ }^{1 *}$

\section{Correction}

After publication of this supplement article [1], it was brought to our attention that reference 10 and reference 12 in the article are incorrect.

As such, please be advised that the correct versions of these references are:

\section{Reference 10:}

Busato F, Bombieri N. BFS-4K: an efficient implementation of BFS for kepler GPU architectures. IEEE Trans Parallel Distrib Syst. 2015; 26(7):1826-38.

\section{Reference 12:}

Aldegheri S, Barnat J, Bombieri N, Busato F, Češka M. Parametric multi-step scheme for gpu-accelerated graph decomposition into strongly connected components. In: Euro-Par 2016: Parallel Processing Workshops - Euro-Par 2016 International Workshops, Grenoble, France, August 24-26, 2016, Revised Selected Papers.2016. p. 519-31.

\section{Author details}

'Department of Computer Science, University of Verona, Strada le Grazie, 15, Verona, Italy. ${ }^{2}$ Institute of Oncology Research (IOR), Via Vincenzo Vela 6, Bellinzona, Switzerland.

Published online: 27 November 2018

\section{Reference}

1. Bonnici, et al. cuRnet: an R package for graph traversing on GPU. 2018; 19(Suppl 10):356. https://doi.org/10.1186/s12859-018-2310-3.

\footnotetext{
*Correspondence: rosalba.giugno@univr.it

${ }^{1}$ Department of Computer Science, University of Verona, Strada le Grazie, 15, Verona, Italy

Full list of author information is available at the end of the article
}

(c) The Author(s). 2018 Open Access This article is distributed under the terms of the Creative Commons Attribution 4.0 International License (http://creativecommons.org/licenses/by/4.0/), which permits unrestricted use, distribution, and reproduction in any medium, provided you give appropriate credit to the original author(s) and the source, provide a link to the Creative Commons license, and indicate if changes were made. The Creative Commons Public Domain Dedication waiver (http://creativecommons.org/publicdomain/zero/1.0/) applies to the data made available in this article, unless otherwise stated. 